Eastern Illinois University

The Keep

January 2009

\title{
One School, Many Differences: An Assessment Tool for School Counselors and Multicultural Counseling
}

Rebecca L. Tadlock-Marlo

Eastern Illinois University, rltadlockmarlo@eiu.edu

Follow this and additional works at: https://thekeep.eiu.edu/csd_fac

Part of the Student Counseling and Personnel Services Commons

\section{Recommended Citation}

Tadlock-Marlo, Rebecca L., "One School, Many Differences: An Assessment Tool for School Counselors and Multicultural Counseling" (2009). Faculty Research \& Creative Activity. 30.

https://thekeep.eiu.edu/csd_fac/30

This Article is brought to you for free and open access by the Counseling and Higher Education at The Keep. It has been accepted for inclusion in Faculty Research \& Creative Activity by an authorized administrator of The Keep. For more information, please contact tabruns@eiu.edu. 
One School, Many Differences:

An Assessment Tool for School Counselors and Multicultural Counseling 


\begin{abstract}
Multicultural counseling competencies (MCCs) have typically been measured with instruments designed for and normed on mental health professionals (for example, MCCTS-R; HolcombMcCoy, 2001; MCI; Sodowsky, Taffe, Gutkin, \& Wise, 1994; D’Andrea, Daniels, \& Heck, 1991). One published instrument specifically assesses school counselor MCCs (MCCTS-R; Holcomb-McCoy, 2001) but it does not conform to ASCA standards (2010, E.2). Following a set of validation procedures, an instrument designed to specifically assess school counselors' multicultural counseling competencies was created that conforms to American School Counselor Association and Association for Multicultural Counseling and Development standards. Its creation is detailed here and the resulting instrument is presented for examination and consideration.
\end{abstract}

Keywords: Multicultural; Assessment; School Counseling 
Students can face inequality and harsh treatment as schools may unwittingly promote multiculturally insensitive cultural, social, and political agendas. Although, many educational systems strive for egalitarianism and impartiality, the stark reality of inequality for many students in society may be the norm (see for example Cokley, 2006; D'Andrea, 2006; Kozol, 1991). Educational curricula are often designed as a result of political and social ideas formed beyond the concrete walls of schools (Soo Hoo, 2004; Wink, 2005). It is within such curricula that ideals and ways-of-being are taught and reinforced, on the whole, to promote "respectable and moldable" capitalist citizens (Biglow, 1998; Molnar, 2005; Soo Hoo, 2004). In doing so, a school promotes consensus normative values regarding how individuals should carry out their daily lives both to the betterment of themselves and to the greater society. These values are typically culturally embedded; that is, in the U.S., they are grounded in the majority, Westernized, White culture, and, unfortunately, appear to reinforce the "savage inequality" of everyday society (Kozol, 1991; Sue, 2006), creating a type of blindness or block among cultures. This block impedes mutual understanding and respect and can promote discord among cultural groups, both in schools and in the general public.

There are many people poised to be advocates for change in schools. School counselors are especially situated to intervene to create multiculturally sensitive educational systems. Multiculturally competent school counselors who are well-trained in the American School Counselor Association (ASCA, 2008) model of counseling can be instrumental in assessing and implementing social change in schools. Unfortunately, fairly limited research exists pertaining to school counselors' base-level multicultural counseling competencies (MCCs). The few instruments that do exist to measure MCCs do not seem to cover the realities of the school counselor role. Indeed, the measures that have been developed are typically normed on 
community mental health professionals and not school counselors (cf., CCCI-R; LaFromboise, Coleman, \& Hernandez, 1991; MAKSS; D’Andrea, Daniels, \& Heck, 1991; MCAS-B; Ponterotto, Rieger, Barrett, \& Sparks, 1994; MCI; Sodowsky, Taffe, Gutkin, \& Wise, 1994). As school counselors' roles vary greatly from those of community mental health professionals, it becomes increasingly important to have a measure normed on school counselors. Also, previous measures have been developed primarily on quantitative data rather than incorporating qualitative elements for a more comprehensive evaluation. A case can be made, however, that when developing culturally sensitive measures, constructs should be examined qualitatively as well as quantitatively (Whiston, 2002).

The primary purpose of this study was to develop a self-report instrument that accurately measures school counselors' perceived MCCs. This instrument was based on the standards set out by both ASCA (2010, E.2; ASCA, 2008) and the Association for Multicultural Counseling and Development (AMCD, 1996). In addition, this study attempted to accurately define and determine how practicing school counselors understand the terms "multiculturalism" and "MCCs." Finally, the study addressed the following questions: (a) What are the multicultural counseling competencies of school counselors? (b) How do school counselors perceive their own multicultural counseling competencies? and (c) What suitable instrument could be developed based on a validation study?

\section{Overall Research Sequence}

A mixed-method design was used, incorporating both quantitative and qualitative research methods. The overall research sequence conducted to develop the initial instrument began with the examination of current instruments designed to assess MCCs. An initial instrument was created, exposed to a pilot group, altered, edited, and then sent to a focus group 
of practicing school counselors. After implementing changes suggested by both the pilot group and the focus group, the 110-item instrument was finally distributed to a sample of school counselors in the United States. An exploratory factor analysis was conducted on the data collected, resulting in specific domains in which school counselors implement multicultural competencies.

Participants in this study were three-tiered. The first tier consisted of four internshiplevel Master's students in a pilot group. The second was a focus group of six practicing school counselors. The final group was a sample of 387 school counselors from various regions in the United States. Power analysis and a subject-to-variable ratio provided an estimate of the number of participants needed for a study to anticipate optimum sample size needed for stable, significant, generalizable results. Based on the power analysis, using an alpha of .05, a population size greater than 20,000, and a response distribution of $50 \%$, a recommended sample size of 377 participants was projected (Raosoft, 2004). The sample involved ( $n=397)$ was just over that figure.

\section{Creation of the Initial Instrument}

\section{Purpose}

As the significance of effective multicultural counseling competencies becomes more evident for school counselors so, too, does the importance of accurately assessing such competencies. Currently, there is only one recognized assessment specifically designed for school counselors based on AMCD standards (Holcomb-McCoy, 2001), and there are no assessments integrating ASCA standards. Holcomb-McCoy and Day-Vines (2004) describe this area of research as still in its infancy; therefore, relatively limited valid and reliable constructs exist specifically for school counselors. Most instruments have been developed to assess 
counselor trainees or other non-school based mental health professionals' MCCs (HolcombMcCoy \& Day-Vines, 2004). The assessments most commonly used in research include: the Multicultural Competencies and Explanatory Statements-Revised (MCCTS-R; HolcombMcCoy, 2001), the Multicultural Counseling Inventory (MCI; Sodowsky, Taffe, Gutkin, \& Wise, 1994), the Multicultural Counseling Awareness Scale (MCAS-B; Ponterotto, Rieger, Barrett, \& Sparks, 1994), the Multicultural Awareness-Knowledge-and Skills Survey (MAKSS; D’Andrea, Daniels, \& Heck, 1991), and the Cross Cultural Counseling Inventory Revised (CCCI-R; LaFromboise, Coleman, \& Hernandez, 1991).

Currently, no clear consensus on how to accurately and comprehensively assess multicultural counseling competencies of school counselors exists (Holcomb-McCoy \& DayVines, 2004; Kocarek, Talbot, Batka, \& Anderson, 2001). Of the instruments commonly researched, each measures slightly different aspects of multiculturalism (Kocarek et al., 2001; Pope-Davis \& Dings, 1994). For instance, some assessments focus on behaviors, while others focus on beliefs, awareness, or issues related to an individual's personhood. The ways in which the subscales vary among the instruments suggest school counselors' MCCs are still not fully understood (Kitaoka, 2005). Therefore, it is critical that additional instruments and theories are developed to accurately and efficiently assess school counselors' MCCs.

Even though multicultural competencies have most commonly been defined as a culmination of awareness, knowledge, and skills (Dunn, Smith, \& Montoya, 2006; HolcombMcCoy \& Day-Vines, 2004; Kocarek et al., 2001; Penderson, 1991, Pope-Davis \& Dings, 1994; Pope-Davis \& Dings, 1995; Ridley \& Kleiner, 2003; Sue, Arredondo, \& McDavis, 1992; Sue, Bernier, Durran, Feinberg, Pendersen, Smith, et al., 1982), there is a significant need to consider alternative concepts that may contribute to a counselor's multicultural proficiency (Kitaoka, 
2005). When viewed as a composite palate from which to draw, the MCCTS-R, MCI, MCAS-B, MAKSS, and CCCI-R can all provide valuable resources to reference when building an instrument specifically to assess practicing school counselors' MCCs.

\section{Procedures}

The instrument designed and implemented was based on standards for MCCs set forth by ASCA (2010) and AMCD (1996). In addition, researchers examined the reliability, validity, and factors of multiculturalism with the MCI, MCAS-B, MAKSS, CCCI-R, and MCCTS-R, then identified key themes within said instruments. Researchers combined those themes with the aforementioned ASCA and AMCD competencies to construct questions.

The Marlowe-Crowne Social Desirability Scale (Crowne \& Marlowe, 1960) was also integrated into the assessment to identify indications of socially desirable answers provided on

the instrument. A demographics section was developed to gather data regarding gender, training in the area of multicultural counseling competencies, ethnicity, socioeconomic status, experience of working with multicultural populations, and personal experiences with multiculturalism. The developed instrument utilized five-point Likert scale responses, measuring multicultural counseling competencies on a scale of "Strongly Agree" to "Strongly Disagree." The resulting survey had 110 questions, consisting of 22 demographic questions, 75 multicultural questions, and the 13-item Marlow-Crowe Social Desirability Scale.

\section{Pilot Group}

\section{Purpose and Procedures}

The instrument was first distributed to and critiqued by a pilot group to ensure that it encompassed a comprehensive view of multiculturalism and multicultural counseling competencies, to consider readability, and to identify awkward questions. Each member of the 
pilot group was instructed of their role, reviewed the instrument individually, and then discussed potential alterations in a group meeting.

The pilot group consisted of four school counseling Master's-level internship students from a Counsel for Accreditation of Counseling and Related Educational Programs (CACREP) accredited Educational Psychology department at a Midwestern University. Members were selected based on referral by colleagues and professors who identified each as a multiculturally competent school counseling intern. Master's students in their internship experience were used because of the insight they could provide from practicing and implementing their skills in their current school placements, as well as their extensive training in multiculturalism. All participants were Caucasian $(\mathrm{N}=4)$, three were female and one was male, and they ranged in age from 24 to 32 years. Participants reported interning in rural $(\mathrm{N}=2)$, suburban $(\mathrm{N}=1)$, and inner city $(\mathrm{N}=1)$ schools, in grade-levels ranging from high schools $(\mathrm{N}=2)$, a middle school $(\mathrm{N}=1)$, and an elementary school $(\mathrm{N}=1)$.

\section{Pilot Group Outcomes}

After submission to the pilot group, several questions were altered or deleted. Based on the group's recommendations, questions regarding the schools' levels of multiculturalism were altered so that the person completing the instrument could evaluate a school's multiculturalism based on AMCD's (1996) definition of “multicultural." The pilot group also recommended adding the state in which the school counselor worked to the demographics section. This question was added to assess generalizability of the results in future research and to observe where the instrument distribution was located. Other questions required slight alterations for readability and grammatical errors. 
Members agreed the domains presented were sufficient to assess multicultural competencies of school counselors. These domains included Collaboration, Assessment, Curriculum and School Environment, Counseling, and Personal Factors. These represent school counselors' skills, knowledge, and personal/professional awareness regarding the importance of working efficiently and effectively with stakeholders, using assessment strategies appropriately, developing and implementing multicultural curricula, applying counseling interventions, and displaying insight into the influence of personal heritage on self and others.

The pilot group noted school counselors' multicultural competency would be evidenced through awareness and knowledge of their multicultural skills as they relate to stakeholders. These aspects may reveal themselves through collaborating with stakeholders, implementing appropriate counseling skills, being aware of self, using appropriate assessment strategies, and promoting an environment supportive of multiculturalism. Pilot group members did not suggest any new domains and agreed none of the presented domains should be removed. Therefore, the original five domains were submitted to the focus group.

\section{Focus Groups}

\section{Purpose and Procedure}

Practicing school counselors who consented to participate in a focus group were invited to join an on-line discussion forum. The forum was used to collect qualitative data and to strengthen the trustworthiness of the instrument. The focus group forum allowed the primary researcher (first author) a parsimonious manner to collect data from various geographical regions, reduce potential peer-pressure, and fill the gap of qualitative data in the multicultural research field (Krueger \& Casey, 2000; Moddox, 1998). Data were analyzed using Corbin and Strauss' (2009) grounded theory qualitative analysis. 
Counselor educators subscribing to CESNET-L listserve were asked to nominate multiculturally competent practicing school counselors. The nominated practicing school counselors were then contacted privately for a description of the research. Description of the study was provided and content to participate received. Six individuals were invited to and agreed to participate in a private discussion thread set-up to allow for continued discussion over two months. Membership was limited to six to help ensure optimal participant comfort and adequate subject depth and breadth, given the potentially emotional nature of the topic under discussion (Kitzinger, 1995; Krueger \& Casey, 2000; Morgan, 1996; Powell \& Single, 1996). Members were assigned chat names and passwords to maintain participant anonymity and were asked to log onto a specific group thread at set times. Open-ended questions were attached to the initial survey email to provide a structure to the focus group and to gain insight about strengths and limitations of the instrument. Participants in the focus group were from California, Georgia, Illinois, Kentucky, New York, and Texas. Of the six participants, two were Caucasian women, one was an African American female, one was a Caucasian male, one was a Caucasian-African American male, and the other member was an Asian American male. Participants' ages range from 28 to 62, with a mean age of 39.17 and a standard deviation of 12.09. In addition, five participants reported having earned a Master's degree as their highest earned degree, while one participant reported a Doctorate degree.

These school counselors reported experience working as a school counselor ranging from three to 14 years, with a mean of 7.16 years $(\mathrm{sd}=3.80)$; and working in rural $(\mathrm{N}=3)$, suburban $(\mathrm{N}=1)$, and inner city $(\mathrm{N}=2)$ schools. Members noted that they currently worked in high schools $(\mathrm{N}=3)$, middle schools $(\mathrm{N}=2)$, and an elementary school $(\mathrm{N}=1)$. They also reported that 
their schools ranged from extremely heterogeneous/multicultural $(\mathrm{N}=2 ; 33.33 \%)$, to somewhat multicultural $(\mathrm{N}=3 ; 50.00 \%)$, to extremely homogeneous/lacking diversity $(\mathrm{N}=1 ; 16.67 \%)$.

\section{Focus Group Outcomes}

The saturation point regarding themes and emergent data, or point in which no new data transpired from the discussion, occurred after two focus group meetings. After themes were gathered and analyzed from the focus group, a summary was written and sent to the participants for a member check of data interpretation. A third meeting, designed as a follow-up member check, produced no new information so the focus group online chat forum was terminated.

As a result of the focus group's data, two questions that appeared redundant and two questions that seemed likely to extract socially-desirable answers were deleted. Two questions were added to follow up on questions from previous items for validity response checks. Focus group members discussed adding a domain related to interpersonal relationships, but participants came to the view that the essence of this domain was highlighted through other areas in the instrument. After appropriate refinements, the final 108-item instrument, named One School, Many Differences, covered five domains, which included: (a) Collaboration, (b) Assessment, (c) Curriculum and School Environment, (d) Counseling Skills, and (e) Personal Factors.

\section{Counselor Survey}

\section{Purpose and Procedures}

For the purpose of obtaining base-line quantitative data concerning the instrument's factor structure and reliability, the instrument was distributed via email to practicing school counselors around the United States. Potential school counselor participants were culled from 21 states. Twenty-five State Departments of Education were randomly selected, called by the first author to provide information about the research, and asked to submit a link to the 
instrument, via email, to their current practicing school counselors. Four state's Department of Education declined the study; 21 state's Department of Education agreed to participate and distribute an informed consent and link to the research through their state listserv. When individual school counselors received the invitation to participate from their Department of Education, they were informed that the primary purpose of the study was to develop a selfreport construct that accurately measures the perceived multicultural counseling competencies of school counselors. Therefore, they were asked to fill out a demographics questionnaire and respond to Likert scale questions, ranging from "1 strongly disagree" to "5 strongly agree", based on their personal reactions to the questions presented.

A total of 387 practicing school counselors responded to the invitation to participate. Most participants identified themselves as Caucasian ( $\mathrm{N}=326 ; 84.5 \%)$, with others indicating African American $(\mathrm{N}=24 ; 6.2 \%)$, Hispanic American/Latino(a) $(\mathrm{N}=7 ; 1.8 \%)$, Asian American or Pacific Islander $(\mathrm{N}=6 ; 1.6 \%)$, Chicano(a) or Mexican American $(\mathrm{N}=2 ; .5 \%)$, Native American/American Indian or Alaskan Native $(\mathrm{N}=2 ; .5 \%)$. Fourteen respondents reported ethnicities not listed (3.6\%), and six participants did not respond to this question (1.6\%). The vast majority had Master's degrees (363; 94.0\%), while 19 had Doctorates and four held terminal Bachelor's degrees.

Most participants identified themselves as heterosexual $(\mathrm{N}=356 ; 92.5 \%)$, while 25 participants identified themselves as homosexual (6.5\%), four as bisexual (1.0\%), and two did not respond to this question (.5\%). A plurality reported being Christian $(\mathrm{N}=179 ; 46.3 \%)$, with 62 Catholic (16.0\%), 62 Protestant (16.0\%), 12 Jewish (3.1\%), eight Unitarian (2.1\%), eight Agnostic (2.1\%), six Buddhist (1.6\%), one Muslim (.3\%), one Atheist (.3\%), and two participants did not respond to the question (.5\%). Participants reported being strongly spiritual 
$(\mathrm{N}=155 ; 40.2 \%)$, to moderately spiritual $(\mathrm{N}=138 ; 35.8 \%)$, to semi-spiritual $(\mathrm{N}=81 ; 21.0 \%)$, to not spiritual $(\mathrm{N}=12 ; 3.1 \%)$.

Participants reported currently working in inner city $(\mathrm{N}=28 ; 7.2 \%)$, urban $(\mathrm{N}=55$; $14.2 \%)$, suburban $(\mathrm{N}=114 ; 29.5 \%)$, rural $(\mathrm{N}=166 ; 42.9 \%)$, subrural $(\mathrm{N}=16 ; 4.1 \%)$, and multiple school locations $(\mathrm{N}=8 ; 2.1 \%)$. Participants also reported working in high schools $(\mathrm{N}=160$; $41.3 \%)$, middle schools ranging from fifth to eighth grade $(\mathrm{N}=105 ; 27.1 \%)$, elementary schools ranging from $\mathrm{K}-4$ schools $(\mathrm{N}=96 ; 24.8 \%), \mathrm{K}-8$ schools $(\mathrm{N}=12 ; 3.1 \%)$ and $\mathrm{K}-12$ schools $(\mathrm{N}=$ $14 ; 3.6 \%)$. Participants further reported that the school they currently worked in ranged from extremely heterogeneous $(\mathrm{N}=68 ; 17.6 \%)$, to somewhat diverse $(\mathrm{N}=196 ; 50.6 \%)$, to extremely homogeneous and lacking diversity $(\mathrm{N}=123 ; 31.8 \%)$.

Based on AMCD's (1996) definition of diverse, 72 (18.7\%) participants reported working primarily with students who were culturally different from themselves, 161 (41.8\%) frequently worked with students culturally different from themselves, 88 (22.9\%) sometimes worked with students culturally different from themselves, 60 (15.6\%) rarely worked with culturally diverse students, and four (1.0\%) participants reported never working with students culturally different from themselves.

The sample contained participants from 21 states, with 71 (18.3\%) from New York, 49 (12.7\%) from North Carolina, 49 (12.7\%) from South Carolina, and 35 (9\%) from West Virginia. Hence, more than half of the participants $(\mathrm{N}=204 ; 52.7 \%)$ were from the Eastern United States.

\section{School Counselor Survey Outcomes}

Once quantitative data were obtained from the sample $(\mathrm{N}=387)$, data were analyzed using SPSS 17.0. EFA and reliability analyses were conducted first to pursue Research Question Three ("What suitable instrument could be developed based on a validation study?"). This 
research question was investigated first to ensure a solid factor structure from which to analyze the remaining two research questions. Descriptive statistics based on the factor structure derived from Research Question Three were then used to pursue Research Question Two ("How do school counselors perceive their own multicultural counseling competencies?").

After analyzing the quantitative data, results were triangulated with the qualitative data and previous research, resulting in the exploration of additional convergences and inconsistencies. Research Question One ("What are the multicultural counseling competencies of school counselors?') was addressed using this triangulation of qualitative and quantitative data to assess perceptions of multicultural counseling competencies of school counselors from diverse viewpoints. This triangulation of data augments the validity and completeness of the research conducted (Barbour, 2001; Mathison, 1988; Tobin \& Begley, 2004).

\section{Factor Analysis}

\section{Purpose and Procedures}

An analysis was conducted of the quantitative data to evaluate the construct validity and internal consistency reliability using exploratory factor analysis (EFA) and Cronbach's alpha. In this research, an EFA was used to identify questions that described both common and unique variance in the newly developed instrument, One School Many Differences (OSMD), while also eliminating questions with high multicollinearity and low contribution to explaining variance in the instrument. Reliability Crinbach's alpha score were then compared for the derived factor structures of the EFA to assess the best fit model while retaining variance explained by items.

\section{Results}

Pre-analysis. The instrument, One School Many Differences (OSMD), originally contained 20 demographic items, the 13-point Marlow-Crowe Social Desirability Scale, and 75 
cultural questions, spread among five domains, which included: (a) Collaboration, (b)

Assessment, (c) Curriculum and School Environment, (d) Counseling Skills, and (e) Personal Factors. Only the 75 cultural items were used in the EFA and all questions were checked to avoid reverse coding. Three Collaboration questions were discarded because they were on a dichotomous Likert-scale, rather than the range used for other questions, and therefore could not be used in an EFA. Four questions in Curriculum and School Environment were also discarded because they were validity response checks for questions, and therefore would produce high multicollinearity if left within the instrument. With these seven items removed from the instrument, 68 items remained for the initial EFA.

Initial analysis. An EFA was used to assess responses $(\mathrm{N}=387)$ to the 68 -item instrument. As the factors extracted were not highly correlated using an oblique rotation, varimax rotation was used in all EFAs. The Scree-plot (Figure 1) suggested four factors may be sufficient to establish a concise instrument, with minimal loss of information, low multicollinearity, and uncompromised variance explained by items. However, theory derived from the qualitative pilot group and focus group assessment of data suggested using five factors. Therefore, five factors were extracted for the first factor analysis and then compared to a fourfactor structure.

Insert Figure 1 About Here

Five-factor solution. With 68 items in the instrument, $36.39 \%$ of the variance was explained by the five factors extracted. Items were removed if they had cross loadings or did not load on any factors using a threshold of .40 . This procedure was repeated until a simple structure 
was achieved. Using this method, 37 items were not accommodated. The final version consisted of 31 questions and $45.85 \%$ of their variability explained by the five factors extracted. A fourfactor model was then conducted based on data observed from the Scree plot and the qualitative pilot group.

Four-factor solution. For comparison purposes, an EFA was run to extract four factors. With all 68 items in the instrument, $33.59 \%$ of the variance was explained by the four factors. After removing items that loaded on multiple factors and those not loading on any factors with a threshold of .40 , a total of 37 items remained to achieve a simple structure. At that point, $38.29 \%$ of the variance of these items was accounted for by the four factors extracted.

\section{Internal Consistency Reliability}

Cronbach's alphas of the items grouped by both the five-factor and four-factor solutions were compared with those from the original instrument. Table 1 presents the reliabilities for all three potential instruments: the original scale, the five-factor scale, and the four-factor scale.

In instrument development, it is preferable to develop scales with the fewest number of questions possible without compromising reliability (Henson, Capraro, \& Capraro, 2004;

Raubernheimer, 2004; Statsoft, 2008). Therefore, number of questions, coefficient alphas, and logical, theory-grounded item loadings were considered during the analyses.

Original scale. When assessing internal reliability, the original full scale of 68 items had a Cronbach's alpha of .93 for all variables. The Cronbach's alphas for the original subscales were reported as .56 for the 12 -item Collaboration scale, .78 for the 5-item Assessment scale, .78 for the 10-item Curriculum and School Environment scale, .84 for the 20 -item Counseling scale, and .85 for the 21 -item Personal scale. These reliabilities were then compared with those from the instrument developed using the five-factor solution. 
Insert Table 1 About Here

Five-Factor Scale. For the five-factor scale, coefficient alphas were .86 for the 31 item whole instrument, .85 for the 13-item Factor 1, .82 for the 10-item Factor 2, .66 for the 4-item Factor 3, .68 for the 2-item Factor 4, and .78 for the 2-item Factor 5. In this factor solution, only two questions loaded on Factors 4 and 5. In both of these factors, the two questions that loaded asked the same information from different perspectives, so the reliabilities were expected to be very strong. Coefficient alphas from the original scale and the five-factor instrument were then compared with those from the four-factor instrument.

Four-Factor Scale. For the four-factor scale, the coefficient alpha was .87 for the 37 item whole scale. Reliabilities for individual factors were .86 for the 14-item Factor 1, Assessment of School Environment; .73 for the 10-item Factor 2, Reflection of Personal Culture; .76 for the 9item Factor 3, Interpersonal Relationships; and .57 for the 4-item Factor 4, Collaboration. Table 2 presents the factor loadings for the four-factor EFA model. Although the last Factor's reliability was lower than that for Factor 4 or Factor 5 in the five-factor scale, it remained comparable to the original Collaboration subscale. When contrasted to the original scale, the reliabilities of each subscale were comparable, thereby providing merit for this shorter scale.

Insert Table 2 About Here

The instruments obtained from both a five-factor and a four-factor EFA were assessed and evaluated. The four-factor instrument was chosen because there was a clear connection 
among items for each of the loadings, and the factors remained similar to those from the original instrument. For instance, items within the individual factors assessed specific domains, such as a collaborative role or counseling skills. In addition, the original instrument contained the subscales (a) Collaboration, (b) Assessment, (c) Curriculum and School Environment, (d) Counseling, and (e) Personal Factors. In comparison, the four-factor model closely paralleled these domains and integrated the interpersonal relationship factor considered during the focus group discussions.

The four-factor model contained the subscales (a) Collaboration, (b) Assessment of School Environment, (c) Reflection of Personal Culture, (d) and Interpersonal Relationships. With regards to the internal consistency reliability, the whole scale and each subscale of the fourfactor instrument were comparable to those of the original.

Although the variance explained by the four-factor solution (37.20\%) was lower than the five-factor solution (47.71\%), the variance remains respectable (Henson, Capraro, \& Capraro, 2004). With one less factor and six more questions, the total variance explained by the fourfactor model would be expected to be lower than the instrument with fewer questions and more factors of the five-factor model. When assessing the five-factor scale, there were significant issues in the fourth and fifth subscales. Specifically, there were only two items that loaded on them and the two questions asked for similar information; therefore their reliabilities were expected to be higher than reported ( $\alpha=.68$ and $\alpha=.78$ respectively). The five-factor structure also had no clear unity among items for the factor groupings. In contrast, the four-factor structure paralleled the original scale and integrated the relational component discussed in the focus group. These strengths of the four-factor structure, when contrasted with the flaws of the five-factor structure culminated into sufficiently valid reasons to accept the four-factor scale. 


\section{Factor Names}

With the determined factor loadings of the EFA, new domains were examined and renamed. The first factor combined two subscales from the original instrument; Assessment and Curriculum/School Environment. This 14-item subscale was named "Assessment of School Environment" because all Assessment and Curriculum items loaded on this factor. The remaining items on this factor highlight school counselors' fluency in assessing aspects of environment within the school. Factor 2 was named "Reflection of Personal Culture" and paralleled the Personal domain of the original instrument. This 10-item subscale highlights school counselors' ability to self-reflect on personal culture, influence of cultural values, and ability to filter assumptions. The third factor, "Interpersonal Relationships", emphasizes school counselors' relationships with self and stakeholders. This 9-item subscale incorporates items from Personal, Counseling, and Collaboration from the original instrument. Factor 4 is comprised of four collaboration items from the original Collaboration domain. This factor retained the "Collaboration" label and highlights school counselors" ability to work well with stakeholders. Combined, these four factors represent a means of conceptualizing school counselor multicultural competence in a manner reflective of ASCA and AMCD standards. Such a structure allows for more detailed exploration of the research questions. With a fourfactor structure constructed for assessing school counselor MCC, each of the domains named, and each audited for reliability, the three research questions may be fully examined.

\section{Assessment of Research Question Three}

In response to Research Question Three ("What instrument can be developed after a validation study?"), factor analysis indicates an instrument including 37 items (14 focused on Assessment of School Environment, 10 on Reflection of Personal Culture, 9 on Interpersonal 
Relationships, and 4 on Collaboration) can accurately assess MCCs of school counselors without altering internal consistency reliability. With that in mind, only items from the newly constructed four-factor instrument were included in the analysis of Research Question Two.

\section{Research Question Two Assessed}

Only items from the newly constructed four-factor instrument were included in the analysis of Research Question Two: "How do school counselors perceive their own multicultural counseling competencies?" Each of the four factors was analyzed to assess school counselors' perceptions of their multicultural counseling competencies. As the instrument was neither normed nor fully validated, only descriptive statistics were used; specifically modes, means, and standard deviations. When evaluating participants' responses to five-point Likert scale items (ranging from "1 strongly disagree”, "2 generally disagree”, "3 neutral”, "4 generally agree”, to "5 strongly agree") on the four factors, the mean response was computed by adding together the individual items of the subscale, dividing this sum by the total number of items in the subscale, and calculating a descriptive mean.

When assessing the school environment (Factor 1), practicing school counselors selfreported a range from neutral to general agreement in regard to multicultural competence in this area $(\bar{x}=3.47, \mathrm{sd}=.54 ;$ mode $=4)$. Participants also responded as being neutral to general agreement in being multiculturally competent when reflecting on personal culture (Factor 2$)(\bar{x}=$ 3.64, $\mathrm{sd}=.47$, mode $=4$ ). Interpersonal relationships (Factor 3 ) was the strongest factor, as participants reported agreement to being multiculturally competent in this component $(\bar{x}=4.32$, $\mathrm{sd}=.34$, mode $=5$ ). When assessing collaboration efforts (Factor 4$)$, school counselors responded with general agreement to being multiculturally competent $(\bar{x}=4.09, \mathrm{sd}=.49$, mode $=4)$. 


\section{Instrument Development}

Qualitative and quantitative methodologies were used as complementary approaches to evaluate and develop a construct that assesses the multicultural competencies of school counselors. As a result of implementing and triangulating both qualitative and quantitative approaches to previous research, data have sound trustworthiness and reliability, ensuring the construct measured multicultural counseling competencies from the perspective of practicing school counselors. Previous research was triangulated with these qualitative and quantitative data points to assess the congruence and inconsistencies of the data. Triangulation strengthened the methodology, completeness, and trustworthiness of both the instrument and the research findings by adding robust perspectives to the research question (Creswell \& Miller, 2000; Tobin \& Begley, 2004).

When considered, the multicultural competencies of counselors are generally viewed through the domains of knowledge, skills, and awareness (Dunn, Smith, \& Montoya, 2006; Holcomb-McCoy \& Day-Vines, 2004; Kocarek et al., 2001; Penderson, 1991; Pope-Davis \& Dings, 1994; Sue et al., 1992). However, contradictory to previous research, data from the current research suggest that school counselors should have competence in (a) Collaboration, (b) Assessment of School Environment, (c) Reflection of Personal Culture, (d) and Interpersonal Relationships. Based on items within the four-factor model instrument, knowledge, skills, and awareness may be seen as intertwined within the four components, but do not solely constitute multicultural competence specific to school counselors.

As suggested by previous research, the Collaboration domain highlights the need for school counselors to collaborate effectively with stakeholders, such as working well with parents and being able to effectively use community resources (ASCA, 2010; Holcomb-McCoy, 2001). 
Current and past research acknowledges school counselors must be able to efficiently and appropriately assess the school environment, which includes purposeful evaluation of the effects of teachers' or administrators' attitudes on minority students' development or assessing cultural issues prominent within the school and community (Arredondo, et al., 1996; Fassinger \& Richie, 1997; Sue et al., 1992). The Reflection of Personal Culture domain also replicates previous research insight suggesting the importance of counselor self-awareness and understanding how their own cultural identity may influence their perceptions, actions, beliefs, and biases (Constantine, 2001; Holcomb-McCoy, 2005; Holcomb-McCoy et al., 2008). The final domain, Interpersonal Relationships, emphasizes school counselors' ability to build effective interpersonal relationships with students, parents, community agencies, faculty, staff, administration, and other stakeholders. Through these interpersonal relationships, the school counselor manifests the essence of multicultural competencies, working effectively with stakeholders to promote a school environment that embraces diversity, encourages collaborative relationships, and promotes self-understanding (ASCA, 2010).

\section{Limitations}

Although this research has strengths as a result of the qualitative and quantitative procedures, limitations exist as well. For instance, the instrument presented in this research is neither normed nor fully validated. In addition, because of the limited psychometric properties of this instrument, more complex analyses were restricted for the current data; therefore, only means, standard deviations, and modes were used. Another limitation is found in the sampling procedures for the quantitative analysis. For example, only 25 states were contacted to participate in the study and only 21 states were represented in the sample; therefore, not all practicing school counselors were given equal opportunity to participate in the research. Pilot 
team members were contacted only at a single university, and focus group participants were only contacted through Counselor Educators on the CESNET-L listserv. Both of these participant samples were based on convenience rather than random sampling procedures.

For the quantitative data, participation was only possible if the state's Department of Education permitted distribution of the instrument. Moreover, even if the state did agree to distribute the instrument, some individual counties within states declined participation. As a result of these constraints, school counselor participation was restricted to states that agreed to participate, counties that agreed to distribute the research, and volunteers who consented to participate. Therefore, approximately 50 percent of the sample responses were collected from only three States: New York, North Carolina, South Carolina and West Virginia. As a result, the geographical representation from the sample data was restricted. An additional limitation is the self-report nature of the construct. With self-reported information, socially desirable answers may emerge.

\section{Conclusion}

The continued development of this instrument will help advance research in the fields of school counseling and multiculturalism. Currently, research specific to multicultural counseling competencies of school counselors is limited. Prior to this research, only one instrument assessing multiculturalism has been developed for school counselors based on AMCD standards (Holcomb-McCoy, 2001) and no existing assessment integrates ASCA standards. Therefore, it is critical to continue development of an instrument complying with both AMCD and ASCA standards to assess school counselors' perceptions of multicultural competence.

This newly constructed instrument may help redefine aspects of multicultural counseling competencies, specifically those delineated to school counselors. Currently, in the field of 
multicultural research, the most commonly used domains to assess multicultural competencies are knowledge, skills, and awareness (Dunn, Smith, \& Montoya, 2006; Holcomb-McCoy \& DayVines, 2004; Kocarek et al., 2001; Penderson, 1991; Pope-Davie \& Dings, 1994; Sue et al., 1992). Contrasting these three presented domains, data from the qualitative research and the exploratory factor analysis suggested that the multicultural competencies for school counselors can be divided into four domains, including (a) Collaboration, (b) Assessment of School Environment, (c) Reflection of Personal Culture, (d) and Interpersonal Relationships. In each of these domains, components of knowledge, skills, and awareness are interwoven, creating a comprehensive, practical assessment of school counselors' multicultural competencies. A confirmatory factory analysis should be implemented with a larger, more diverse representative sample to further validate this four-factor structure. Continuous investigations concerning factor loadings that represent school counselor multicultural competencies may reveal additional latent theory to be analyzed.

Future research may implement multiple focus groups of practicing school counselors so that a larger pool of data can be triangulated in assessing the components that comprise the multicultural counseling competencies of school counselors. Triangulating this rich data would further strengthen the rigor and depth of the qualitative data, advancing the general understanding of multicultural counseling competencies of school counselors.

Based on the analyses run with the newly constructed instrument, school counselors generally reported being multiculturally competent on all four domains. However, there was a large standard deviation with the reported means, so school counselors' perceptions in the given domains varied. Psychometric values assessed suggested practicing school counselors in this sample reported being more competent in interpersonal relationships $(\bar{x}=4.32$, sd $=.34)$ and 
collaboration $(\bar{x}=4.09, \mathrm{sd}=.49)$ than assessing school environment $(\bar{x}=3.47, \mathrm{sd}=.54)$ and reflecting on personal culture $(\bar{x}=3.64, \mathrm{sd}=.47)$. Therefore, for school counselors to establish a comprehensive understanding of multicultural competencies it is important for them to continue fostering interpersonal relationships and collaboration. They can use these strengths to foster development and progression in their ability to assess multicultural school environments and reflect on their own personal culture.

Essential to future research is to norm this instrument, establishing reliability and validity so that school counselors will have a valid, reliable, practical instrument to assess multicultural competencies. Through assessing their competencies through a validated measure, school counselors can gain insight into their roles as a school counselor and the ways in which multicultural counseling competencies may influence their performance in these roles. By assessing these competencies, school counselors can focus on domains in which to improve on, to the betterment of themselves, their students, and their school community. 


\section{References}

American School Counselors Association (2008). ASCA National Model. Alexandria, VA: Author.

American School Counselors Association (2010). Ethical standards for school counselors. Alexandria, VA: Author.

American School Counselor Association (2004a). ASCA National Standards for Students. Alexandria, VA: Author.

American School Counselor Association (2004b). Position statements: Cultural diversity. Retrieved July 15, 2008 from http://www.schoolcounselor.org/content.asp?contentid=249

Arredondo, P., Toporek, M.S., Brown, S., Jones, J., Locke, D.C., Sanchez, J., \& Stadler, H. (1996). Operationalization of the multicultural counseling competencies. AMCD: Alexandria, VA.

Barbour, R. (2001). Checklist for improving rigor in qualitative research: a case of the tail wagging the dog? Education and debate, 322, 1115-1117.

Biglow, B. (1998). The human lived behind the labels: The global sweatshop, Nike, and the race to the bottom. In W. Ayers, J. A. Hunt, \& T. Quinne (Eds.) Teaching for social justice. New York, NY: Teachers College Press.

Cokley, K. (2006). The impact of racialized schools and racist (mis)education on African American students' academic identity. In M. Constantine and D. W. Sue (Eds.), Addressing racism: Facilitating cultural competence in mental health and educational settings (pp. 127-144). Hoboken, NJ: Wiley.

Constantine, M. (2001). Multicultural training, self-construals, and multicultural competence of school counselors. Professional School Counseling, 4, 202- 213. 
Corbin, J.M., \& Strauss, A.L. (2009). Basics of qualitative research: Techniques and procedures for developing grounded theory ( $3^{\text {rd }}$ ed.). Thousand Oaks, CA: Sage Publications.

Creswell, J., \& Miller, D. (2000). Determining validity in qualitative inquiry. Theory into practice, 39, 124-130. doi: doi:10.1207/s15430421tip3903_2

Crowne, D., \& Marlowe, D. (1960). A new scale of social desirability independent of psychopathology. Journal of Consulting Psychology, 24, 349-354. doi:10.1037/h0047358

D. Andrea, M. (2006). In liberty and justice for all: A comprehensive approach to ameliorating the complex problems of White racism and White superiority in the United States. In M. Constantine and D. W. Sue (Eds.), Addressing racism: Facilitating cultural competence in mental health and educational settings (pp. 251-270). Hoboken, NJ: Wiley.

D’Andrea, M., Daniels, J., \& Heck, R. (1991). Evaluating the impact of multicultural counseling training. Journal of Counseling \& Development, 70, 143-150.

Dunn, T., Smith, T., \& Montoya, J. (2006). Multicultural competency instrumentation: A review and analysis of reliability generalization. Journal of Counseling and Development, 84, 471-482. doi:10.1002/j.1556-6678.2006.tb00431.x

Fassinger, R., \& Richie, B. (1997). Sex matters: Gender and sexual orientation in training for multicultural counseling competency. In D. Pope-David and H. Coleman (Eds.) Multicultural counseling competencies: Assessment, education and training, and supervision (83-110). Thousand Oaks, CA: Sage Publications.

Henson, R., Capraro, R., \& Capraro, M. (2004). Reporting practice and use of exploratory factor analysis in educational research journals. Research in the Schools, 11, 61-72. 
Holcomb-McCoy, C. (2001). Exploring the self-perceived multicultural counseling competence of elementary school counselors. Professional School Counseling, 4, 195208.

Holcomb-McCoy, C. (2004). Assessing the multicultural competence of school counselors: A checklist. Professional School Counseling, 7, 178-183.

Holcomb-McCoy, C. (2005). Investigating school counselors' perceived multicultural competence. Professional School Counseling, 8, 414-423.

Holcomb-McCoy, C., \& Day-Vines, N. (2004). Exploring school counselor multicultural competence: A multidimensional concept. Measurement and Evaluation in Counseling and Development, 37, 154-162.

Holcomb-McCoy, C., Harris, P., Hines, E., \& Johnston, G. (2008). School counselors’ multicultural self-efficacy: A preliminary investigation. Professional School Counseling, $11,166-178$.

Kitaoka, S.K. (2005). Multicultural Counseling Competencies: Lessons from assessment. Journal of Multicultural Counseling and Development, 33, 37-47. doi:10.1002/j.21611912.2005.tb00003.x

Kitzinger, J. (1995). Qualitative research: Introducing focus groups. British Medical Journal, 311, 299-302. doi:10.1136/bmj.311.7000.299

Kocarek, C., Talbot, D., Batka, J., \& Anderson, M. (2001). Reliability and validity of three measures of multicultural competency. Journal of Counseling and Development, 79, 486496. doi:10.1002/j.1556-6676.2001.tb01996.x

Kozol, J. (1991). Savage Inequalities: Children in America's Schools. New York, NY: Crown. 
Krueger, R., \& Casey, M. (2000). Focus groups: A practical guide for applied research. Thousand Oaks, CA: Sage Publications.

LaFromboise, T, Coleman, H., \& Hernandez, A. (1991). Development and factor structure of the Cross-Cultural Counseling Inventory-Revised. Professional Psychology: Research and Practice, 22, 380-388. doi:10.1037//0735-7028.22.5.380

Mathison, S. (1988). Why Triangulate? Educational Researcher, 17, 13-17. doi: $10.2307 / 1174583$

Moddox, K. (1998). Virtual panels add real insight for marketers. Advertising Age, 69, 34-40.

Molnar, A. (2005). The sky's the limit: Trends in schoolhouse marketing since 1990. In School Commercialism: From democratic ideal to market commodity (73-89). New York, NY: Routledge.

Morgan, D. (1996). Focus groups. Annual Review of Sociology, 22, 129-152. doi:10.1146/annurev.soc.22.1.129

Penderson, P. (1991). Multiculturalism as a generic approach to counseling. Journal of Counseling and Development, 70, 6-12.

Ponterotto, J., Rieger, B., Barrett, A., \& Sparks, R. (1994). Assessing multicultural counseling competence: A review of instrumentation. Journal of Counseling and Development, 72, 316-322.

Pope-Davis, D., \& Dings, J. (1995). The Assessment of multicultural counseling competencies. In J. Ponterotto, J. Casa, L. Suzuki, and C. Alexander (Eds.), Handbook of multicultural counseling (pp. 287-311). Thousand Oaks, CA: Sage Publications. 
Pope-Davis, D., \& Dings, J. (1994). An empirical comparison of two self-report multicultural counseling competency inventories. Measurement and Evaluation in Counseling and Development, 27, 93-102.

Powell, R., \& Single, H. (1996). Methodology matters: Focus groups. International Journal for Quality in Health Care, 8, 499-504.

Raosoft. (2004). Sample size calculator. Retrieved October 1, 2008, from http://raosoft.com/samplesize.html

Raubenheimer, J. (2004). An item selection procedure to maximize scale reliability and validity. South African Journal of Industrial Psychology, 30, 59-64.

Ridley, C., \& Kleinder, A. (2003). Multicultural counseling competence: History, themes, and issues. In D. Pope-Davis, H. Coleman, W. Ming Liu, and R. Toporek (Eds.) Handbook of multicultural competencies in counseling and psychology (pp. 3-20). Thousand Oaks, CA: Sage Publications.

Sodowsky, G., Taffe, R., Gutkin, T., \& Wise, S. (1994). Development of the Multicultural Counseling Inventory: A self-report measure of multiple competencies. Journal of Counseling and Development, 41, 137-148.

Soo Hoo S. (2004). We change the world by doing nothing. Teacher Education Quarterly, 4 (1), 199- 211.

Statsoft Inc. (2008). Principal components and factor analysis. Retrieved February 14, 2009 from http://www.statsoft.com/textbook/stfacan.html 
Sue, D.W. (2006). The invisible whiteness of being: Whiteness, white supremacy, white privilege, and racism. In M. Constantine and D. W. Sue (Eds.), Addressing racism: Facilitating cultural competence in mental health and educational settings (pp. 15-32). Hoboken, NJ: Wiley.

Sue, D.W., Arredondo, P., \& McDavis, R.J. (1992). Multicultural counseling competencies and standards: A call to the profession. Journal of Multicultural Counseling and Development, 20, 644-688. doi:10.1002/j.2161-1912.1992.tb00563.x

Sue, D.W., Bernier, J., Durran, A., Feinberg, L., Pendersen, P., Smith, E., et al. (1982). Position paper: Cross-cultural counseling competencies. The counseling Psychologist, 10, 45-52. doi:10.1177/0011000082102008

Tobin, G., \& Begley, C.M. (2004). Methodological rigour within qualitative framework. Methodological Issues in Nursing Research, 48, 388-396. doi:10.1111/j.13652648.2004.03207.x

Whiston, S.C. (2002). Response to the past, present, and future of school counseling: Raising some issues. Professional School Counselor, 5, 148-155.

Wink, J. (2005). Critical pedagogy: Notes from the real world. Boston, MA: Pearson Education. 


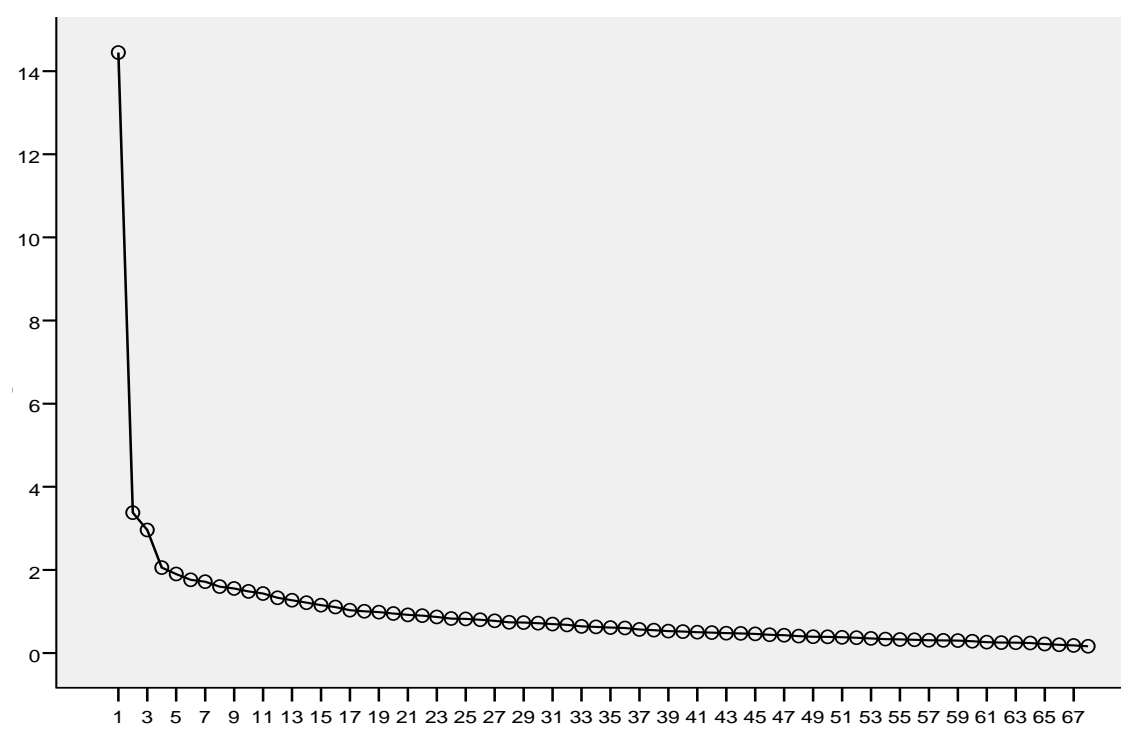

Component Number

Figure 1. Scree plot of initial EFA with 68 items.

Table 1

Coefficient alphas for original, five-factor, and four-factor scales $(N=387)$

\begin{tabular}{|c|c|c|c|c|c|c|c|c|}
\hline \multicolumn{3}{|l|}{ Original } & \multicolumn{3}{|l|}{5 Factor } & \multicolumn{3}{|l|}{4 Factor } \\
\hline Scale & Items & $\alpha$ & Scale & Items & $\alpha$ & Scale & Items & $\alpha$ \\
\hline Whole Scale & 68 & .93 & Whole Scale & 31 & .86 & Whole Scale & 37 & .87 \\
\hline \multirow[t]{3}{*}{ Assessment } & 5 & .78 & Factor 1 & 13 & .85 & Assessment & 14 & .86 \\
\hline & & & & & & of School & & \\
\hline & & & & & & Environment & & \\
\hline Personal & 21 & .85 & Factor 2 & 10 & .82 & Reflection of & 10 & .73 \\
\hline
\end{tabular}




\begin{tabular}{|c|c|c|c|c|c|c|c|c|}
\hline & & & & & & Culture & & \\
\hline Counseling & 20 & .84 & Factor 3 & 4 & .66 & $\begin{array}{l}\text { Interpersonal } \\
\text { Relationships }\end{array}$ & 9 & .76 \\
\hline Collaboration & 12 & .56 & Factor 4 & 2 & .68 & Collaboration & 4 & .57 \\
\hline Curriculum/ & 10 & .78 & Factor 5 & 2 & .78 & & & \\
\hline \multicolumn{9}{|l|}{ School } \\
\hline Environmen & & & & & & & & \\
\hline
\end{tabular}

Note. Table 1 compares three instruments' coefficient alphas: original scale, five-factor postexploratory factor analysis scale, and four-factor post-exploratory factor analysis scale.

Coefficient alphas were compared for each item within the subscale and the instrument as a whole to assess the instruments' reliability.

Table 2

Results from the four-factor EFA with orthogonal rotation $(N=387)$

Components

\begin{tabular}{|c|c|c|c|}
\hline Scale Item & 1 & 4 & $\mathrm{~h}^{2}$ \\
\hline Assessment 2 & .767 & & .434 \\
\hline Assessment5 & .735 & & .328 \\
\hline Assessment4 & .725 & & .440 \\
\hline CurriculumSE2 & .673 & & .355 \\
\hline Assessment3 & .560 & & .487 \\
\hline Counseling3 & .555 & & .319 \\
\hline CurriculumSE7 & .548 & & .558 \\
\hline Counseling6 & .536 & & .391 \\
\hline
\end{tabular}




\begin{tabular}{|c|c|c|c|c|c|}
\hline CurriculumSE10 & .536 & & & & .500 \\
\hline CurriculumSE1 & .499 & & & & .525 \\
\hline CurriculumSE3 & .498 & & & & .393 \\
\hline Personal6 & .486 & & & & .452 \\
\hline CurriculumSE4 & .461 & & & & .314 \\
\hline Personal20 & .461 & & & & .386 \\
\hline Personal15 & & .647 & & & .410 \\
\hline Counseling19 & & .638 & & & .357 \\
\hline Collaboration 2 & & .543 & & & .280 \\
\hline Counseling20 & & .532 & & & .313 \\
\hline Personal11 & & .494 & & & .384 \\
\hline Personal17 & & .489 & & & .364 \\
\hline Counseling12 & & .480 & & & .377 \\
\hline Personal14 & & .464 & & & .241 \\
\hline Personal2 & & .439 & & & .439 \\
\hline Personal16 & & .420 & & & .274 \\
\hline Personal4 & & & .723 & & .451 \\
\hline Personal18 & & & .624 & & .533 \\
\hline Counseling13 & & & .593 & & .314 \\
\hline Personal19 & & & .540 & & .378 \\
\hline Personal7 & & & .471 & & .431 \\
\hline Personal21 & & & .460 & & .234 \\
\hline Counseling1 & & & .443 & & .474 \\
\hline Collaboration14 & & & .438 & & .238 \\
\hline Counseling18 & & & .416 & & .245 \\
\hline Collaboration 12 & & & & .696 & .467 \\
\hline Collaboration $4 \mathrm{R}$ & & & & .658 & .466 \\
\hline Collaboration1 & & & & .553 & .194 \\
\hline Collaboration7 & & & & .490 & .422 \\
\hline \multicolumn{6}{|l|}{ Table 2 (continued) } \\
\hline & \multicolumn{5}{|c|}{ Components } \\
\hline & 1 & 2 & 3 & 4 & \\
\hline Eigenvalues & 7.547 & 2.700 & 2.201 & 1.718 & \\
\hline$\%$ of Total Variance & 20.397 & 7.297 & 5.948 & 4.644 & \\
\hline Cumulative Variance & 20.397 & 27.694 & 33.642 & 38.286 & \\
\hline
\end{tabular}

Note. Table 2 depicts the factor loadings, eigenvalues, and the communality, or reliability of the indicator $\left(\mathrm{h}^{2}\right)$, for the 4 factor EFA of the instrument. 